\title{
Evaluation of the Mechanical Properties of Anorectal Tissues and Muscles by Shear Wave Elastography in Anal Fıssure Disease
}

\author{
Nazmi Ozer ${ }^{1}$ and Feride Fatma Gorgulu² \\ ${ }^{1}$ Department of General Surgery, Adana City Training and Research Hospital, University of Health Sciences, Turkey \\ ${ }^{2}$ Department of Radiology, Adana City Training and Research Hospital, University of Health Sciences, Turkey
}

\begin{abstract}
Objective: To evaluate the mechanical properties of the tissues and muscles in the anal region with the shearwave elastography for anal fissure etiology.

Study Design: Descriptive study.

Place and Duration of Study: Adana City Training and Research Hospital, Turkey, from March2019 to March 2020.

Methodology: In this study, 30 patients (fissure group), who were diagnosed with anal fissure in the outpatient clinic; and 20 patients (control group), who did not have any problem in anal examination were included. The anorectal tissues and muscles mechanical properties(elasticity,compliance and stiffness) were compared with the shear wave elastography values.Fissure area,internal anal sphincter,external anal sphincter and levator ani muscles elastographic measurements was performed with 5-18 MHzin lithotomy position, at rest and with Valsalva maneuver.

Results: In elastographic measurement of fissure area (fissure) and normal anorectal tissue (control, AFE); control group values were significantly higher than the fissure group values $(p<0.001$, and padj $<0.001$, respectively). Control group valuesof internal anal sphincter in rest and Valsalva maneuver (IAS-R, and IAS-V, respectively) were significantly higher than the fissure group values $(p<0.001$, padj $<0.001$, and $p<0.001$, padj $<0.001$, respectively). There was no significant difference between the elastographic measurement values in rest and valsalva maneuver of the external anal sphincter (EAS-R and EAS-V) $(p>0.05)$. Elastographic measurement values of levator ani muscle (LAM) resting state; were significantly higher in thefissure group than the control group ( $p<0.001$, and padj $<0.001$, respectively). Elastographic cut-off values that differentiate the fissure group from control group were found to be $\leq 1 \mathrm{kPa}$ forAFE group, $\leq 44 \mathrm{kPa}$ forlAS-R, $\leq 0.4 \mathrm{kPa}$ forlAS-V,and $>11 \mathrm{kPa}$ for LAM, respectively.

Conclusion: In anal fissure disease, tissues mechanical properties measured by shear wave elastography showed increased tissue stiffness, which may be added to etiology of this disease.
\end{abstract}

Key Words: Anal fissure, Ultrasonography, Shear wave elastography, Anal sphincter, Tissue elasticity, Tissue stiffness.

How to cite this article: Ozer N, Gorgulu FF. Evaluation of the Mechanical Properties of Anorectal Tissues and Muscles by Shear Wave Elastography in Anal Fissure Disease. J Coll Physicians Surg Pak 2020; 30(11):1133-1137.

\section{INTRODUCTION}

Anal fissure is a common benign anorectal disease.Its reported reasons include increased internal anal sphincter pressure, prolonged constipation or diarrhea, and feeding with low-fiber diets. ${ }^{1-5}$ But the elasticity of the anal muscle and support tissue, and loss of compliance of this region relation to the disease has not beenstudied so far.

In anal fissure pathophysiology, internal anal sphincter muscle spasm and tissue ischemia are thought to play a role. ${ }^{6}$ Ischemia recovery occurs with fibrosis.

Correspondence to: Dr. Nazmi Ozer, Department of General Surgery, Adana City Training and Research Hospital, University of Health Sciences, Turkey E-mail: nazmiozer83@gmail.com

Received: September 07, 2020; Revised: October 19, 2020; Accepted: October 28, 2020

DOI: https://doi.org/10.29271/jcpsp.2020.11.1133
This situation causes the loss of elasticity of the tissues in the anal region even anal stenosis may occur after recurrent disease and recovery periods.

Shear wave elastography is a type of ultrasound elastography, used for diagnosis of soft tissue diseases in liver, prostate, thyroid, breast, and muscle, providing information about the elasticity, stiffness, and compliance of thesetissues. ${ }^{7-9}$ Thus, it may allow evaluation whether these factors contribute to fissure formation in anal fissure disease.

The mechanical properties of tissues include compliance, elasticity and stiffness. Elasticity is the ability of a tissue to be deformed by an external force and to reach its original shape and size when this force is removed.Stiffness can be explained as the situation in the tissue with loss of elasticity. Compliance is expressed as the change in volume against unit pressure change in elastic structures. ${ }^{10-12}$ As elasticity decreases, compliance decreases and tissue stiffness increases. The higher the elastographic measurement values, the higher the 
tissue elasticity and compliance, the lower the tissue stiffness. ${ }^{10-12}$ Sincethere is no previous study in theliterature on whether the mechanical properties of the muscle and support tissue in this region contribute to the formation of the disease; the objective of this study was to evaluate the mechanical properties of the tissue and muscle in the perianal region with shear wave elastography methodin patients with anal fissures compared to controls.

\section{METHODOLOGY}

This study was carried out between March 2019 and March 2020 atAdana City Training and Research Hospital, Turkey. It was performed prospective randomised on 50 adult patients. Thirty patients, who applied to the general surgery outpatient clinic with the complaint of pain and constipation in the anal region, who were diagnosed with anal fissure in anal examination, and 20 patients with normal anal examination were included (fissure and control group).Anal pain was evaluated with the Wong-Baker faces pain rating scale (WBFPS). ${ }^{13}$ The constipation was evaluated as functional and non-functional. ${ }^{14}$ Ethics Committee approval was obtained from Adana City Training and Research Hospital Clinical Research Ethics Committee on 27/02/2019 with 29/397 decision number. Patient information was obtained from the Hospital Information System and polyclinic files.

The patients were examined by a single general surgery specialist, and the diagnosis was made in outpatient clinic conditions, by inspection and digital examination.Patients with a WBFPS pain score of 4 and above during anal examination, and patients with functional constipation were included in the study. Patients with a pain score below 4 points, patients with non-functional constipation, patients with atypical localisation and multiple fissures $(>2)$, patients with underlying inflammatory bowel disease, malignancy, HIV, syphilis, tuberculosis-like diseases, were excluded from the study.

In this technique, a shear wave is formed perpendicular to the displacement in the axial plane, created by the ultrasound wave and $10^{4}$ times more atenue than classical US.Using this shear wave velocity, the elasticity of the tissue is measured by the formula $E=3 x V^{2}$. $E$ is Young's modulus in $\mathrm{kPa}$ (kiloPascals, the module that reports the elastic properties of tissue) and $V$ is the shearwave speed in $\mathrm{cm} / \mathrm{sec}^{15,16}$

The patients were evaluated by a single radiologist using the Aixplorer ${ }^{\circledR}$ devicein the Radiology Clinic of the Hospital, in lithotomy position using the linear $\mathrm{SL}(5-18 \mathrm{MHz})$. After the localisation of the tissue and muscle with B-mode ultrasound,10-second shots were taken in order to make shear wave elastographic measurements; and the measurements were obtained at rest and with Valsalva maneuver. ${ }^{17}$ Elastographic values of the anal fissure area, the internal anal andexternal anal sphincter at rest state and with Valsalva maneuver, and levatorani muscle were measured. In the control group, elastographic measurement of normal anorectal tissue was performed instead of the fissure area, all other parameters were evaluated jointly in fissure and control groups (Figure 1). Elastographic measurement value of the anal fissure area in fissure group and normal anorectal tissue elastographic measurement values in the control group were expressed as AFE. elastographic measurement values of the levator ani muscle at rest are expressed as LAM. Elastographic measurements of the internal anal sphincter at rest and during the Valsalva maneuver were labelledIAS-R and IAS-V, respectively. Elastographic measurements of the external anal sphincter at rest and during the Valsalva maneuver were labelledEAS-R and EAS-V, respectively.

The quantitative data was expressed as mean $\pm S$. D,minimum and maximum values; while qualitative data were expressed as numbers and percentages. Normality control of continuous variables was done by Shapiro-Wilk test.Parametric tests were used because the variables were suitable for normal distribution. Student's t test was used to compare the mean between anal fissure and control group. Since age and BMI values did not show a homogeneous distribution according to the groups, $p_{\text {adj }}$ values were calculated by covariance analysis. Receiver operating characteristic (ROC) analysis was used to evaluate the sensitivity, specificity and performance of variables in separating groups. The distribution of gender by groups was evaluated with the Chi-square test. MedCalc and SPSS 21 programmes were used to analyse the data.Values of $p<0.05$ were considered significant.

\section{RESULTS}

In the anal fissure group $(n=30), 21$ patients were women (70\%) and 9 patients were men( $30 \%)$; while 13 patients were women $(65 \%)$ and 7 patients were men (35\%) in the control group $(n=20)$. Gender distributions was homogeneous $(p=0.710)$.

The mean age was $32.33 \pm 8.77$ ( 19 -49 years) in the anal fissure group, and was $37.65 \pm 8.9$ (18-50 years) in the control group. There was a statistically significant difference between the groups in terms of average age $(p=0.042)$.

In terms of body mass index, the BMI value of the anal fissure group was $28.57 \pm 3.97\left(22-40 \mathrm{~kg} / \mathrm{m}^{2}\right)$, and the BMI value of the control group was $32.3 \pm 6.22\left(23-45 \mathrm{~kg} / \mathrm{m}^{2}\right)$. A statistically 6 on 21 patients $(70 \%)$ and at 12 o'clock align on 9 patients (30\%). Table I describes the elastography measurement values in the studied group showing a loss of elasticity in the anal fissure group. For AFE, the cut-off value in separating the fissure group from the control group was found to be $\leq 1 \mathrm{kPa}$. According to this value, success rate of separating the sick people was calculated $60.0 \%$ and success rate of separating the healthy people was calculated as $85.0 \%$ in AFE group. The performance of AFE in separating patients and healthy people was found to be $A \cup C=0.798(p<0.001)$.

The cut-off value for IAS-R in separating the fissure group from the control group was found to be $\leq 44 \mathrm{KPa}$. According to this value, success rate of separating the diseased tissue was calculated as $90.0 \%$ and success rate of separating the healthy tissue was calculated as $95.0 \%$ in IAS-R group. Performance of IAS-R in healthy people was found to be $A U C=0.984(p<0.001)$. 


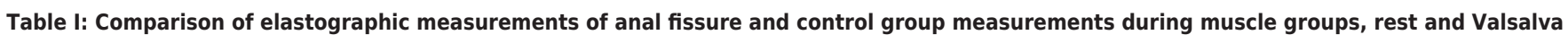
maneuver unit: $\mathbf{k P a})$.

\begin{tabular}{|c|c|c|c|c|c|c|}
\hline & \multicolumn{2}{|c|}{ Anal fissure } & \multicolumn{2}{|c|}{ Control } & \multirow[b]{2}{*}{$\mathbf{p}$} & \multirow[b]{2}{*}{$\mathbf{p}_{\text {adj }}$} \\
\hline & Mean $\pm s d$ & Min-max & Mean $\pm s d$ & Min-max & & \\
\hline AFE & $1.35 \pm 0.91$ & $0.2-3$ & $2.74 \pm 1.38$ & $0.65-5$ & $<0.001$ & $<0.001$ \\
\hline LAM & $11.45 \pm 3.73$ & $6-18$ & $7.00 \pm 2.32$ & 3-11 & $<0.001$ & $<0.001$ \\
\hline IAS-R & $36.57 \pm 6.7$ & $25-48$ & $61.04 \pm 11.82$ & $43-80$ & $<0.001$ & $<0.001$ \\
\hline IAS-V & $0.33 \pm 0.12$ & $0.2-0.65$ & $0.63 \pm 0.19$ & $0.2-0.9$ & $<0.001$ & $<0.001$ \\
\hline EAS-R & $19.84 \pm 9.76$ & $3.88-36$ & $19.03 \pm 9.62$ & $3.88-36$ & 0.775 & 0.940 \\
\hline EAS-V & $4.92 \pm 3.39$ & $0.3-15$ & $4.79 \pm 3.38$ & $0.3-14$ & 0.891 & 0.956 \\
\hline
\end{tabular}

p:Student's t test; $p_{\text {adj: }} p$ values arranged according to age and BMI. AFE: Anal fissure and normal anorectal tissue measurement.LAM: Levator ani muscle measurement.IAS-R:Internal anal sphincter rest measurement.IAS-V: Internal anal sphincter valsalva measurement.EAS-R: External anal sphincter rest measurement.EAS-V: External anal sphincter valsalva measurement.

Table II: Cut off values that determine the separation of control and fissure groups as a result of the comparison of the groups among themselves (unit: $\mathrm{kPa}$ ).

\begin{tabular}{|c|c|c|c|c|c|}
\hline & $\operatorname{AUC}(95 \% \mathrm{CI})$ & Cut off & SE $(95 \% \mathrm{Cl})$ & SP $(95 \% \mathrm{CI})$ & $\mathbf{P}$ \\
\hline AFE & $0.798(0.660-0.898)$ & $\leq 1$ & $60.00(40.6-77.3)$ & $85.00(62.1-96.8)$ & $<0.001$ \\
\hline LAM & $0.820(0.686-0.914)$ & $>11$ & $60.00(40.6-77.3)$ & $100.00(83.2-100.0)$ & $<0.001$ \\
\hline IAS-R & $0.984(0.900-1.000)$ & $\leq 44$ & $90.00(73.5-97.9)$ & $95.00(75.1-99.9)$ & $<0.001$ \\
\hline IAS-V & $0.892(0.771-0.962)$ & $\leq 0.4$ & $90.00(73.5-97.9)$ & $85.00(62.1-96.8)$ & $<0.001$ \\
\hline EAS-R & $0.527(0.380-0.670)$ & $>28$ & $20.00(7.7-38.6)$ & $90.00(68.3-98.8)$ & 0.752 \\
\hline EAS-V & $0.513(0.368-0.657)$ & $>2$ & $86.67(69.3-96.2)$ & $20.00(5.7-43.7)$ & 0.874 \\
\hline
\end{tabular}

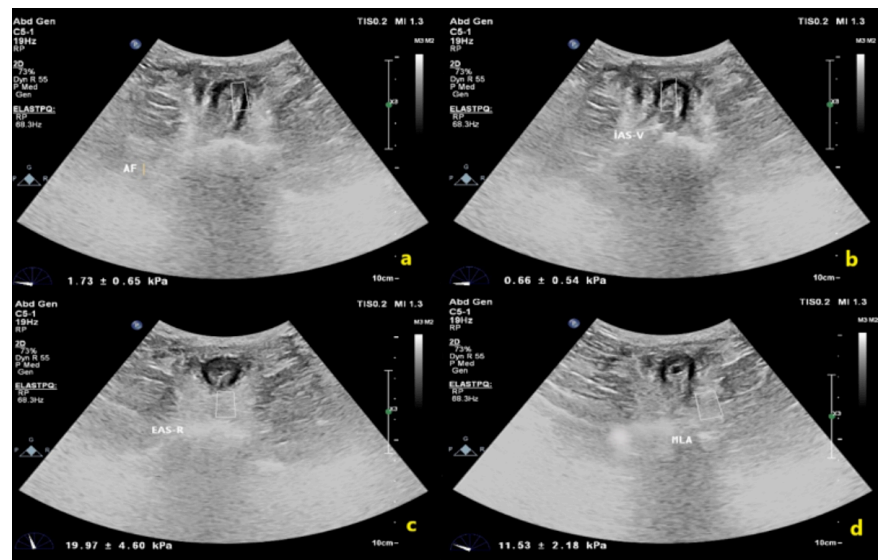

Figure 1: (a) Measurement of anal fissure area with share wave elastography technique, (b) Elastographic measurement of internal anal sphincter in valsalva, (c) Measurement of external anal sphincter at rest, (d) Elastographic measurement of the levator ani muscle at rest.

The cut-off value for IAS-V in separating the fissure group from control group was found to be $\leq 0.4 \mathrm{KPa}$. According to this value, success rate of separating the diseased tissue was calculated as $90.0 \%$ and success rate of separating the healthy tissues was calculated as $95.0 \%$ in IAS-V group. Performance of IAS- $V$ was found to be $A U C=0.892$ $(p<0.001)$.

The cut-off value for LAM in separating the fissure group from control group was found to be $>11 \mathrm{KPa}$. According to this value, success rate of separating the diseased tissue was calculated as $60.0 \%$ and success rate of separating the healthy tissue was calculated as $100.0 \%$ in LAM group. The performance of LAM in separating patients and healthy person was found to be $A \cup C=0.820(p<0.001)$. For EAS-R and EAS-V, it was not statistically significant difference in separating the fissure group from control group $(p>0.05$, Table II, Figure 2).

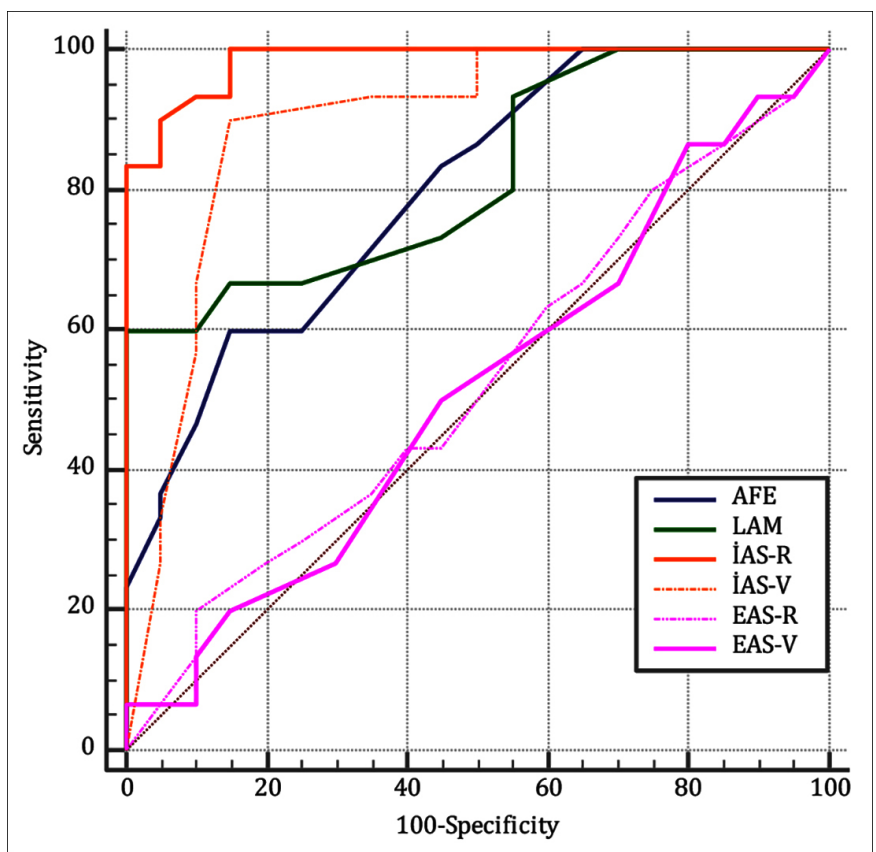

Figure 2: ROC curve analysis according to the muscle groups of the fissure and control groups, rest and valsalva maneuver.

\section{DISCUSSION}

In this study, it was seen that the majority of anal fissure patients were of female gender with low BMI.This informations is parallel with the literature information. ${ }^{18}$

When the anal fissure location was evaluated in this study, it 
occured most frequently at the posterior of the anal canal (6 o'clock align) at a rate of $70 \%$. Literature showed it occurs at a rate of $75 \%$ in the posterior midline of anal canal. ${ }^{19}$

When the elastographic measurements of the anal fissure area and healthy anorectal tissue were examined, it was seen that the elastographic values were significantly higher in the healthy group (control)compared to the patient (fissure) group. This situation led to conclude that control group had higher elasticity of the support tissue in anorectal region, thus higher compliance and lower tissue stiffness compared the fissure group.

When in rest state, elastographic measurement values of the internal anal sphincter were compared.In the fissure and control groups, the measurement values in the control group were significantly higher than the fissure group. This result shows that there is a decrease in the elasticity and compliance in fissure group, so increase in stiffness of the internal anal sphincter muscle fibers. Elastographic values measured during the Valsalva maneuver of the internal anal sphincter are also found to be low in the fissure group and high in the control group, as in the rest state.In the Valsalva maneuver, the elasticity of the fissure group was statistically significantly lower than the control group. Again, this result showed that increased muscle stiffness in the fissure group.

In the elastographic measurements of the external anal sphincter during rest state and Valsalva maneuver, it was observed that there was no significant difference between the fissure and control groups. It was understood that this muscles group had not made a difference, which had similar elasticities in disease formation.

In the elastographic measurements of the levator ani muscle in the fissure and control groups, it was observed that the fissure group had significantly higher values than the control group. In other words, in fissure group, the elasticity and compliance of the levator ani muscle had higher and therefore, less tissue stiffness. This situation made us think that the levator ani muscle may exhibit a compensatory mechanism in the face of pathology.

According to the results of this study, $\leq 1 \mathrm{kPa}$ values in the AFE group, $\leq 44 \mathrm{kPa}$ values in the IAS-R group, $\leq 0.4 \mathrm{kPa}$ values in the IAS- $V$ group, $>11 \mathrm{kPa}$ values in the LAM group were determined as the cut-off values that differentiated the fissure group from the control group. These values help us to evaluate whether the muscle and tissue pathology contributes to the existing disease.

Considering the literature, shear wave elastography measurements in the anal region are available in studies on changes in pelvic floor muscles, especially in pregnancy.In the study by Gachon et al., it was concluded that the risk of perineal trauma is highly correlated with the intrinsic properties of the tissue and this parameter can be determined by shear wave elastography. ${ }^{20}$ In the ELASTOPELV study, in which the pelvic floor of women during pregnancy was evaluated elastographically, the pressure of the levator ani muscle measured as $16 \mathrm{kPa}$ at rest, is in line with this study. ${ }^{21}$

One of the limitations in this study was the failure to measure the levator ani muscle in Valsalva. This measurement was slipped due to loss of ultrasonographic visibility and failure in measurement due to the contraction of the levator ani muscle during the Valsalva maneuver.

In the study by Gachon et al., elastographic measurements of the levator ani muscle were made in the evaluation of pelvic floor diseases, with a failure of approximately $20 \%$ in the measurements made in the valsalva maneuver. ${ }^{22}$

Studies on anal sphincters have been performed with transperineal, exoanal and 3-dimensional ultrasonography techniques, usually on anal sphincter damage, and no elastographic study has been found..$^{23-25}$ This study is the first study on the present subject, and further studies in larger series will contribute to the literature in the diagnosis and treatment of anal fissure.

\section{CONCLUSION}

Mechanical properties of the support tissue and muscles, especially at anorectal region, internal anal sphincter and levator ani muscle play a role in the formation of anal fissure disease.Knowing elastographic cut-off values of perianal muscles and tissues help us to evaluate whether a mechanical component accompanies the etiology in patient with the present disease.

\section{ETHICAL APPROVAL:}

The Ethics Committee approval of our study was obtained before the study started and it was accepted with the approval of the ethics committee at the Adana City Training and Research Hospital Clinical Research Ethics Committee on 27/02/2019 with 29/397 decision number.

\section{PATIENTS' CONSENT:}

Informed consents were obtained from all patients to publish the data concerning this work.

\section{CONFLICT OF INTEREST:}

All authors declared no conflict of interest.

\section{AUTHORS' CONTRIBUTION:}

NO, FFG: Concept, design, supervision, data collection and processing, interpretation, literature search, writing manuscript, critical reviews.

\section{REFERENCES}

1. Leong AF, Seow-Choen F. Lateral sphincterotomy compared with anal advancement flap for chronic anal fissure. Dis Colon Rectum 1995; 38(1):69-71. doi: 10.1007/BF0 2053862. 
2. Nelson RL. Chronic anal fissures. Am Fam Physician 2016; 93(6):498-9.

3. Cook MG, Goligher JC. Carcinoma and epithelial dysplasia complicating ulcerative colitis. Gastroenterol 1975; 68(5): 1127-36.

4. Nelson RL, Thomas K, Morgan J, Jones A. Non surgical therapy for anal fissure. Cochrane Database Syst Rev 2012; 2012(2):CD003431. doi: 10.1002/14651858. CD003431. pub3.

5. Hananel N, Gordon PH. Re-examination of clinical manifestations and response to therapy of fissure-in-ano. Dis of Colon Rectum 1997; 40(2):229-33.doi: 10.1007/ BF02054993.

6. Fält UA, Lindsten $M$, Strandberg S, Dahlberg M, Butt S, Nilsson $E$, et al. Percutaneous tibial nerve stimulation (PTNS): An alternative treatment option for chronic therapy resistant anal fissure. Tech Coloproctol 2019; 23(4): 361-5. doi: 10.1007/s10151-019-01972-5.

7. Wu CH, Chen WS, Park GY, Wang TG, Lew HL. Musculo-skeletal sonoelastography: A focused review of its diagnostic applications for evaluating tendons and fascia. J Med Ultrasound 2012; 20(2): 79-86.

8. Yakut ZI, Turan A, Teber MA. Ultrasound elastography for musculoskeletal applications. Selçuk Tıp Dergisi 2014; 30(2):88-92.

9. Li Y, Snedeker JG. Elastography: Modality-specific approaches, clinical applications, and research horizons. Skeletal Radiol 2011; 40(4):389-97. doi: 10.1007/s00256010-0918-0.

10. Sohail S, Zaman SKU. Diagnostic value of mean elasticity Index as a quantitative shear wave elastography parameter for prediction of malignancy in small suspicious solid thyroid nodules. J Coll Physicians Surg Pak 2020; 30(07):683-7. doi: 10.29271/jcpsp.2020.07.683.

11. Kim JR, Suh CH, Yoon HM, Lee JS, Cho YA, Jung AY. The diagnostic performance of shear-wave elastography for liver fibrosis in children and adolescents: A systematic review and diagnostic meta-analysis. Eur Radiol 2018; 28(3):1175-86. doi: 10.1007/s00330-017-5078-3.

12. Gandhi J, Zaidi S, Shah J, Joshi G, Khan SA. The evolving role of shear wave elastography in the diagnosis and treatment of prostate cancer. Ultrasound Q 2018; 34(4):245-9. doi: 10.1097/RUQ.0000000000000385.

13. Chompu-Inwai $P$, Simprasert $S$, Chuveera $P$, Nirunsittirat $A$, Sastraruji T, Srisuwan T. Effect of nitrous oxide on pulpal anesthesia: A preliminary study. Anesth Prog 2018; 65(3):156-161.doi: 10.2344/anpr-65-02-08.
14. Shin JE, Park KS, Nam K. Chronic functional constipation. Korean J Gastroenterol 2019; 73(2):92-8. doi: 10.4166/kjg. 2019.73.2.92.

15. Bercoff J, Tanter M, Fink M. Supersonic shear imaging: A new technique for soft tissue elasticity mapping. IEEE Trans Ultrason Ferroelectr Freq Control 2004; 51(4):396-409.doi: 10.1109/tuffc.2004.1295425.

16. Eby SF, Song P, Chen S, Chen Q, Greenleaf JF, An KN. Validation of shear wave elastography in skeletal muscle. J Biomech 2013; 46(14):2381-7.doi: 10.1016/j.jbiomech. 2013.07.033.

17. Patcharatrakul T,Rao SS. Update on the pathophysiology and management of anorectal disorders. Gut and liver2018; 12(4):375.doi: 10.5009/gnl17172.

18. Kyriakakis R, Kelly-Schuette K, Hoedema R, Luchtefeld $\mathrm{M}$, Ogilvie J. What predicts successful nonoperative management with botulinum toxin for anal fissure? AmJ Sur 2020;219(3):442-4. doi: 10.1016/j.amjsurg.2019.10.012.

19. Beaty JS, Shashidharan M. Anal Fissure. Clin Colon Rectal Surg 2016;29(1):30-37.

20. Gachon B, Nordez A, Pierre F, Fritel X. Tissue biomechanical behavior should be considered in the risk assessment of perineal trauma at childbirth. Arch Gynecol Obstet 2019;300(6):1821-6. doi: 10.1007/s00404-019-05369-5.

21. Gachon B, Fritel X, Pierre F, Nordez A. In vivo assessment of the elastic properties of women's pelvic floor during pregnancy using shear wave elastography: Design and protocol of the ELASTOPELV study. BMC Musculoskelet Disord2020;21(1):305. doi: 10.1186/s12891-020-03333-y.

22. Gachon B, Nordez A, Pierre F, Fradet L, Fritel X, Desseauve $D$. Invivo assessment of the levator ani muscles using shear wave elastography: A feasibility study in women. Int Urogynecol J 2019;30(7):1179-86. doi: 10.1007/s00192018-3693-4.

23. Eisenberg VH, Valsky DV, Yagel S. Transperineal ultrasound assessment of the anal sphincter after obstetric anal sphincter injury (OASI). Ultrasound Obstet Gynecol 2019;53(2):158-65. doi: 10.1002/uog.19058.

24. Dietz HP. Exoanal Imaging of the anal sphincters. J Ultrasound Med2018;37(1):263-80. doi: 10.1002/jum. 14246. Epub 2017 May 22.

25. Valsky DV, Cohen SM, Lipschuetz M, Hochner-Celnikier D, Yagel S. Three-dimensional transperineal ultrasound findings associated with anal incontinence after intra-partum sphincter tears in primiparous women. Ultrasound Obstet Gyneco/2012;39(1):83-90.doi: 10.1002/uog.10072. 